\title{
The Association between Sentinel Lymph Node Metastasis and Ki-67 Labeling Index
}

\author{
Yu Koyama*, Hiroshi Ichikawa, Jun Sakata, Eiko Sakata, Kumiko Tatsuda, Miki Hasegawa, \\ Chie Toshikawa, Naoko Manba, Mayuko Ikarashi, Toshifumi Wakai \\ Division of Digestive \& General Surgery, Niigata University Graduate School of Medical \& Dental Sciences, Niigata, Japan \\ Email: *yukmy@med.niigata-u.ac.jp
}

Received April 21, 2013; revised May 20, 2013; accepted May 27, 2013

Copyright (C) $2013 \mathrm{Yu}$ Koyama et al. This is an open access article distributed under the Creative Commons Attribution License, which permits unrestricted use, distribution, and reproduction in any medium, provided the original work is properly cited.

\begin{abstract}
Background: The purpose of this study was to elucidate the association between sentinel lymph node (SLN) metastasis and Ki67 labeling index and to elucidate whether Ki-67 was useful or not for prediction of SLN metastasis in breast cancer. Methods: We identified 343 invasive breast cancer patients with sentinel lymph node biopsy (SLNB) from 2003 to 2012. The association between SLN status and clinicopathological features, molecular subtypes and Ki-67 labeling index were evaluated. Results: SLN metastasis was detected in 79 patients $(23.0 \%)$. SLN metastasis was significantly associated with clinical T-stage ( $p=0.0003)$, lymphovascular involvement (LVI) $(p<0.0001)$. Ki-67 labeling index of primary tumor was significantly lower in SLN positive patients $(\mathrm{p}=0.0331)$, and Ki-67 cut-off point of $7.5 \%$ was useful for dividing SLN positive from negative $(\mathrm{p}=0.0197)$. Conclusion: Low value of Ki-67 labeling index, in addition to progression of clinical T-stage and presence of LVI, is significantly associated with SLN metastasis, and it seems to be useful to consider Ki-67 labeling index for SLN metastasis prediction.
\end{abstract}

Keywords: Breast Cancer; Sentinel Lymph Node; Molecular Subtypes; Ki-67 Labeling Index

\section{Introduction}

A lot of studies have elucidated several series of new tumor markers, however, axillary lymph node metastasis still has been a strong prognostic indicator for the patients with invasive breast cancer [1-3]. It is quite difficult to make exact diagnosis of node metastasis, especially, in T1-T2 breast cancer, therefore, sentinel lymph node (SLN) biopsy (SLNB) for clinically N0 breast cancer has already become a standard procedure [4]. However, it has been reported that SLN metastasis was observed in about $30 \%$ in SLNB [5]. A various clinicopathological factors have been identified as independent predictors of axillary lymph node metastasis in early stage breast cancer [6]. These include clinical palpability [7-10], tumor size [7-13], lymphatic or vascular involvement [7-11,13], tumor grade $[7,10]$, hormone receptor (HR) status [12, $13]$, age [8,11,12], and molecular subtypes [3,6,14-22].

Recent clinical trials have suggested no outcome difference in patients with positive SLN between ALND versus no further axillary surgery, raising doubts on the role of SLNB itself $[23,24]$. More recently, a new trial comparing SLNB versus observation when axillary ultra-

*Corresponding author. sound is negative in patients with small breast cancer has been ongoing [25]. Therefore, it seems to be very important to predict axillary node status before SLNB.

On the other hand, Ki-67, a nucleus protein, is an immunohistochemical proliferation marker in many types of cancer and has been widely studied including breast cancer, and independently improved the prediction of treatment response and prognosis [26-28]. $\mathrm{Ki}-67$ has been used to divide luminal $\mathrm{A}(\mathrm{ER} / \mathrm{PR}$ positive, HER negative and Ki-67 < 14\%) and HER2 negative luminal B (ER/PR positive, HER negative and Ki-67 $\geq 14 \%$ ) in molecular subtype classification of St Gallen Consensus [29]. However, the association between Ki-67 expression and SLN metastasis in breast cancer has not been clarified yet.

The purpose of this study was to examine the association between SLN metastasis and $\mathrm{Ki}-67$, and to elucidate whether Ki-67 be useful or not for precidetion of SLN metastasis in breast cancer.

\section{Methods}

\subsection{Patient Selection}

The invasive breast cancer patients who have received 
SNB at Niigata University Hospital between January 2003 and April 2012 were entered in to the present study. This study was a retrospective chart review, and a total of 343 patients were enrolled into the analysis. On the other hand, Ki-67 labeling index was clinically used in our hospital since 2010 because Ki-67 has been recognized as a useful factor at St. Gallen 2009. Therefore, our data of Ki-67 labeling index in the present study was obtained from a total of 117 patients since 2010 .

\subsection{Clinicopathological Assessment}

Immunohistichemical (IHC) ER and PR status was assessed, respectively. Tumors were deemed positive for each receptor if at least $10 \%$ of the invasive tumor cells in a section exhibited nuclear staining. HER 2 expression was also examined by IHC, however, gene amplification assay with fluorescence in situ hybridaization (FISH) method was introduced in case with difficult to decide positive or negative by IHC. And Ki-67 leveling index was also examined by IHC, and the results were expressed as percentage of tumor cells stained by the antibody as described prevuoisly [30]. Lymphovascular involvement (LVI) and Histologic grading were assessed with hematoxylin eosin staining, and histlogic grading was defined according to Scarff-Bloom-Richardson system [31]. SLN metastasis was judged by intraoperative frozen section, however, re-examened with fixed section and postopreratively re-judged. The staging of breast cancer was defined by TNM classification as proposed by the American Joint Committee on Cancer (AJCC). All theses IHC judgement was performed by several well-trained pathologists. According to the results of ER, PR, HER 2 status, patients were grouped into 4 subgroup: ER positive or PR positive, HER 2 negative was categorized as luminal A; ER positive or PR positive, HER 2 positive was categorized as luminal B; ER negative, PR negative and HER 2 positive was categorized as HER 2; ER negative, PR negative and HER 2 negative was categorized as triple negative.

\subsection{Statistical Analysis}

The relationship between SLN metastasis and clinicopahological factors including ER and/or PgR status, Her 2 status, molecular subtypes and Ki-67 leveling index were examined. Statistical analyses were performed using Mann Whitney's U test and Chi-square test, and multivariate analysis were performed using the logistic regression model. The diagnostic accuracy of Ki-67 labeling index was assessed by receiving operating characteristic (ROC) analysis. The area under the ROC curve (AUC) was to measure model disclimination. The AUC can range from 0.5 (which indicates a test with no information) to 1.0 (which indicates a perfect test). The statistical signifi- cance was defined as $\mathrm{P}<0.05$.

\section{Results}

\subsection{Patients Characteristics and Molecular Subtypes}

A total of 343 patients were entered during the period. All patients were female and SLN metastasis was detected in 79 patients $(23.0 \%)$. The mean age of all patients was 55.9 years old, and there was no significant association between age and SLN metastasis $(\mathrm{P}=0.0621)$ (Table 1). There were some deficits of data in histological grade (20 patients), LVI (4 patients), HER 2 status (2 patients) and molecular subtypes ( 2 patients) because of no description in the reports of pathological diagnosis.

Table 1. Association between SLN metastasis and clinicopathological features $(n=343)$.

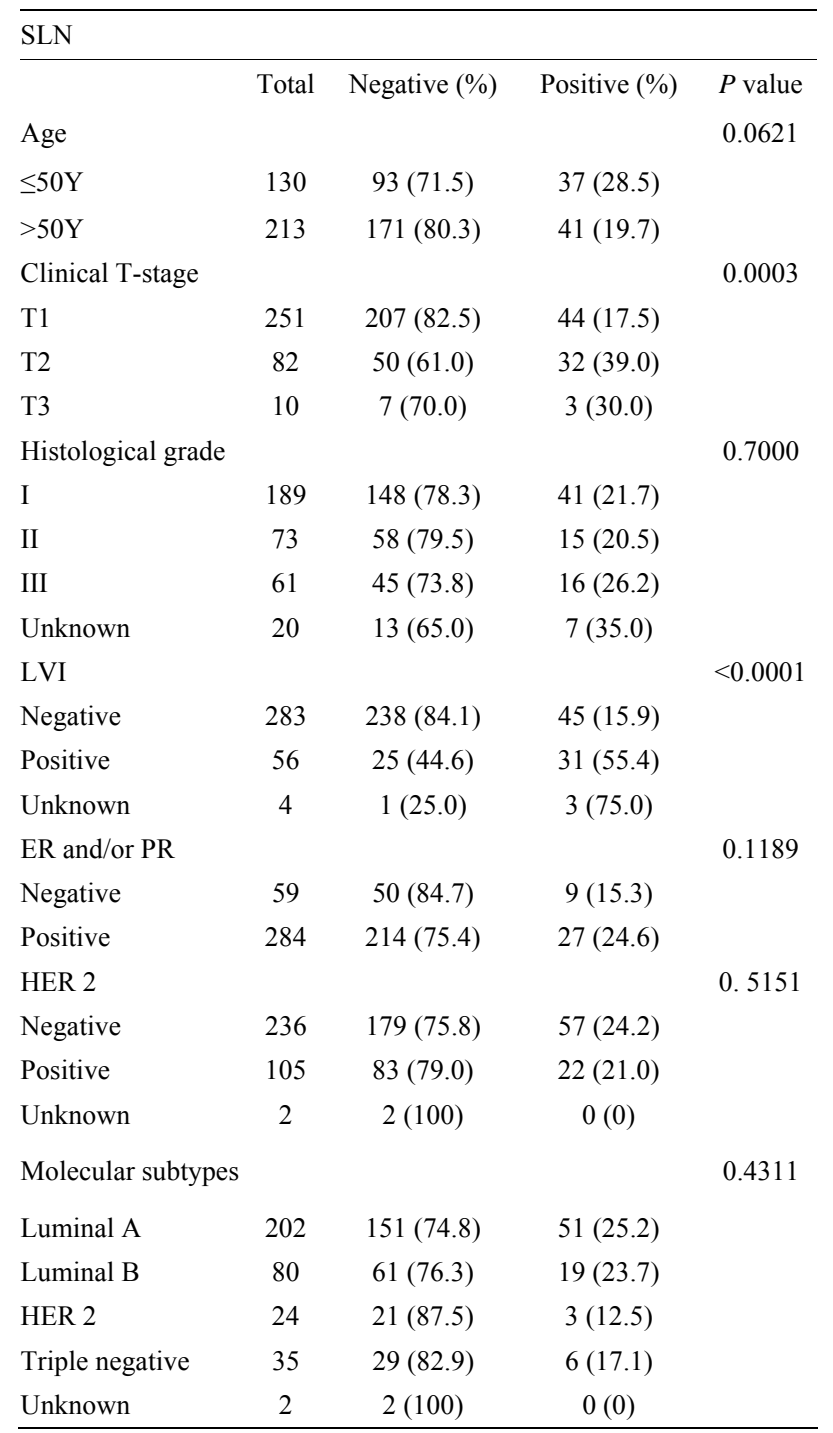

Abbreviations: SLN: sentinel lymph node; LVI: lymphovascular involvement; ER: estrogen receptor; PR: progesterone receptor. 
Clinical T-stage was associated with SN metastasis, and SLN metastasis was more frequent in larger tumor $(\mathrm{P}$ $=0.0003)$. LVI was also strongly associated with SLN metastasis $(\mathrm{P}<0.0001)$.

There was no significant correlation between SLN metastasis and ER and/orPgR status, and HER 2 status. The percentage distribution of molecular subtypes among 341 patients in this study was as follows: luminal A in $59.2 \%$, luminal $\mathrm{B}$ in $23.5 \%$, HER 2 in $7.0 \%$, and triple negative in $10.3 \%$. There was also no significant association between SLN metastasis and molecular subtype classification.

\subsection{Ki-67 Expression and SLN Metastasis}

We compared Ki-67 expression (\%) between SLN positive and negative patients, and the Ki67 expression was significantly lower in SLN positive patients compared with $\mathrm{SN}$ negative patients (mean $\pm \mathrm{SE} ; 14.4 \pm 2.5$ versus $22.2 \pm 1.9, \mathrm{P}=0.0331$ ) (Figure 1).

We tested the cut-off point at Ki-67 14\% according to St Gallen consensus [16]; Ki-67 $\geq 14 \%$ was categorized as high $\mathrm{Ki}-67$ group, and $\mathrm{Ki}-67<14 \%$ was categorized as low $\mathrm{Ki}-67$ group.

The result showed no significant association between Ki-67 expression and SLN metastasis (Table 2). There-

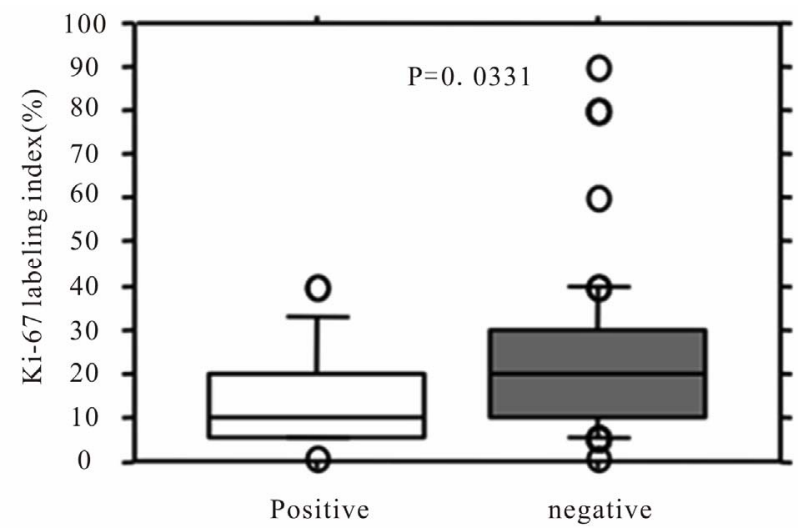

Figure 1. Association between Ki-67 labeling index and SLN status. White square represents sentinel lymph node (SLN) positive group, and gray suare represents SLN negative group.

Table 2. SLN metastasis and Ki-67 cut-off point $(n=117)$.

\begin{tabular}{lccc}
\hline SLN & & & \\
\hline Negative positive & & & \\
& (Cut off at 14\%) & & \\
Ki-67 high & 53 & 8 & $P=0.1003$ \\
Ki-67 low & 42 & 14 & \\
& $($ Cut off at 7.5\%) & & \\
Ki-67 high & 82 & 14 & $P=0.0197$ \\
Ki-67 low & 13 & 8 & \\
\hline
\end{tabular}

fore, we investigated the threshold value of Ki-67 labeling index that differentiated patients who have SLN metastasis by ROC analysis. The ROC analysis identified a cut-off point at 7.5\% (AUC, 0.646; Sensitivity, 86.3; Specificity, 36.4, $\mathrm{P}=0.033$ ) (Figure 2).

Next, we used cut-off point of Ki-67 $7.5 \%$ for reassessment. The result showed no significant association between Ki-67 expression was significantly associated with SLN metastasis by using the cut-off point at Ki-67 7.5\% (Table 2). Multivariate analysis also showed that Ki-67 labeling index was one of the significant factors for predicting SLN metastasis in addition to clinical T-stage and LVI ( $\mathrm{P}=0.016$; relative risk, $4.051,95 \%$ confidence interval, 1.302 - 12.602) (Table 3).

\section{Discussion}

Recent clinical trials have showed no outcome difference in patients with positive SLN between ALND versus no further axillary surgery, raising doubts on the role of SLNB itself. Therefore, it will be becoming important to

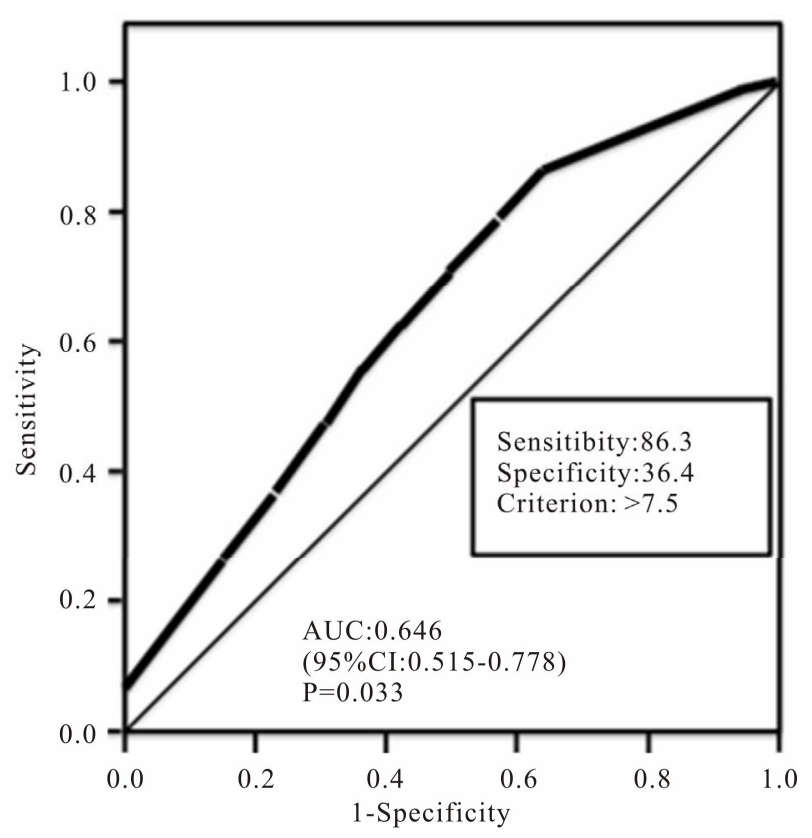

Figure 2. A receiving operating characteristic (ROC) analysis of the accuracy of Ki-67 labeling index is illustrated. Accuracy is measured by calculating the area under the ROC curve (AUC). CI: confidence interval.

Table 3. Multivariate analysis of clinicopathological factors $(\mathbf{n}=117)$.

\begin{tabular}{llll}
\hline$P$ value & $R R(95 \% \mathrm{CI})$ & & \\
\hline Tumor size & T1 vs T2, T3 & 0.021 & $3.580(1.208-10.611)$ \\
LVI & $(-)$ vevs $(+)$ ve & 0.041 & $4.976(1.069-23.159)$ \\
Ki-67 & $>7.5 \%$ vs $\leq 7.5 \%$ & 0.016 & $4.051(1.302-12.602)$ \\
\hline RR: relative risk; CI: confidence interval; LVI: lymphovascular involve- \\
$\begin{array}{l}\text { ment. }\end{array}$
\end{tabular}


predict pathologically node negative before surgery. In our study, clinical T-stage and LVI were significantly associated with SLN metastasis: large tumor and prominent lymphatic and/or vascular invasion was shown to have a higher likelihood of being SLN positive. These findings were in accordance with previous reports [7-13].

Our study could not find out the association between molecular subtype and SLN metastasis, in contrast with previous reports $[3,6,14-22]$. Possible explanation to the discrepancy between previous reports and our results is that the distribution in among subtype might affect the results: HER 2 type was very few $(7.0 \%)$, and this seems to be the reason why low frequency of SLN metastasis in HER 2 subtype was shown in our study.

Ki-67 was also a possible predictor for SLN metastasis in our results: Ki-67 labeling index of primary tumor was significantly lower in SLN positive patients compared with SN negative patients, and this finding has not been reported previously. First, we used Ki-67 cut-off point at $14 \%$ according to St Gallen consensus [29], however, our result showed that $14 \%$ was not appropriate cut-off point for dividing SLN positive from negative. Next, we performed ROC analysis to obtain the most effective Ki-67 cut-off point for dividing SLN positive from negative, and our result showed the validity of $\mathrm{Ki}-67$ cut-off point at $7.5 \%$ for dividing SLN positive from negative.

In conclusion, Ki-67 labeling index, in addition to clinical T-stage and LVI, is significantly associated with SLN metastasis, and it seems to be useful to consider $\mathrm{Ki}$ 67 labeling index for SLN metastasis prediction.

\section{REFERENCES}

[1] P. P. Rosen, S. Groshen, D. W. Kinne and L. Norton, "Factors Influencing Prognosis in Node-Negative Breast Carcinoma: Analysis of 767 T1N0M0/T2N0M0 Patients with Long-Term Follow Up," Journal of Clinical Oncology, Vol. 11, No. 11, 1993, pp. 2090-2100.

[2] "Consensus Statement Treatment of Early-Stage Breast Cancer. National Institutes of Health Consensus Development Panel," Journal of the National Cancer Institute Monographs, No. 11, 1992, pp. 1-5.

[3] J. H. Lee, S. H. Kim, Y. J. Suh, B. Y. Shim and H. K. Kim, "Predictors of Axillary Lymph Node Metastasis (ALNM) in a Korean Population with T1-2 Breast Carcinoma: Triple Negative Breast Cancer Has a High Incidence of ALNM Irrespective of the Tumor Size," Breast Cancer Research and Treatment, Vol. 42, No. 1, 2010, pp. 30-36. doi:10.4143/crt.2010.42.1.30

[4] G. Cserni, S. Bianchi, V. Vezzosi, R. Arisio, R. Bori, J. L. Peterse, A. Sapino, M. Drijkoningen, J. Kulka, V. Eusebi, M. P. Foschini, J. P. Bellocq, C. Marin, S. Thorstenson, I. Amendoeira, A. Reiner-Concin and T. Decker, "Sentinellymph Node Biopsy and Non-Sentinelnode Involvement in Special Type Breast Carcinomas with a Good Prognosis," European Journal of Cancer, Vol. 43, No. 9, 2007, pp. 1407-1414. doi:10.1016/j.ejca.2007.04.004

[5] G. Canavese, M. Gipponi, A. Catturich, C. Vecchio, D. Tomei, G. Nicoló, F. Carli, B. Spina, L. Bonelli, G. Villa, F. Buffoni, P. Bianchi, A. Agnese and G. Mariani, "Technical Issues and Pathologic Implications of Sentinel Lymph Node Biopsy in Early-Stage Breast Cancer Patients," Journal of Surgical Oncology, Vol. 77, No. 2, 2001, pp. 81-87. doi:10.1002/jso.1074

[6] S. J. Crabb, M. C. Cheang, S. Leung, T. Immonen, T. O. Nielsen, D. D. Huntsman, C. D. Bajdik and S. K. Chia, "Basalbreast Cancermolecularsubtype Predicts for Lower Incidence of Axillary Lymph Node Metastases in Primary Breast Cancer," Clinical Breast Cancer, Vol. 8, No. 3, 2008, pp. 249-256. doi:10.3816/CBC.2008.n.028

[7] A. Barth, P. H. Craig and M. J. Silverstein, "Predictors of Axillary Lymph Node Metastases in Patients with T1 Breast Carcinoma," Cancer, Vol. 79, No. 10, 1997, pp. 1918-1922.

doi:10.1002/(SICI)1097-0142(19970515)79:10<1918::AI D-CNCR12>3.0.CO;2-Y

[8] I. A. Olivotto, J. S. Jackson, D. Mates, S. Andersen, W. Davidson, C. J. Bryce and J. Ragaz, "Prediction of Axillary Lymph Node Involvement of Women with Invasive Breast Carcinoma: A Multivariate Analysis," Cancer, Vol. 83, No. 5, 1998, pp. 948-955. doi:10.1002/(SICI)1097-0142(19980901)83:5<948::AIDCNCR21>3.0.CO;2-U

[9] M. J. Silverstein, E. D. Gierson, J. R. Waisman, W. J. Colburn and P. Gamagami, "Predictingaxillary Node Positivity in Patients with Invasive Carcinoma of the Breast by Using a Combination of T Category and Palpability," The Journal of the American College of Surgeons, Vol. 180, No. 6, 1995, pp. 700-704.

[10] M. J. Silverstein, K. A. Skinner and T. J. Lomis, "Predicting Axillary Nodal Positivity in 2282 Patients with Breast Carcinoma," World Journal of Surgery, Vol. 25, No. 6, 2001, pp. 767-772. doi:10.1007/s00268-001-0003-X

[11] C. Gajdos, P. I. Tartter and I. J. Bleiweiss, "Lymphatic Invasion, Tumor Size, and Age Are Independent Predictors of Axillary Lymph Node Metastases in Women with T1 Breast Cancers," Annals of Surgery, Vol. 230, No. 5, 1999, pp. 692-696.

doi:10.1097/00000658-199911000-00012

[12] P. H. Gann, S. A. Colilla, S. M. Gapstur, D. J. Winchester and D. P. Winchester, "Factors Associated with Axillary Lymph Node Metastasis from Breast Carcinoma: Descriptive and Predictive Analyses," Cancer, Vol. 86, No. 8, 1999, pp. 1511-1519.

doi:10.1002/(SICI)1097-0142(19991015)86:8<1511::AID -CNCR18>3.0.CO;2-D

[13] G. Viale, S. Zurrida, E. Maiorano, G. Mazzarol, G. Pruneri, G. Paganelli, P. Maisonneuve and U. Veronesi, "Predicting the Status of Axillary Sentinel Lymph Nodes in 4351 Patients with Invasive Breast Carcinoma Treated in a Single Institution," Cancer, Vol. 103, No. 30, 2005, pp. 492-500. doi:10.1002/cncr.20809

[14] X. Lu, X. Lu, Z. C. Wang, J. D. Iglehart, X. Zhang and A. L. Richardson, "Predicting Features of Breast Cancer with 
Gene Expression Patterns," Breast Cancer Research and Treatment, Vol. 108, No. 2, 2008, pp. 191-201. doi:10.1007/s10549-007-9596-6

[15] H. Liu, Q. Fan, Z. Zhang, X. Li, H. Yu and F. Meng, "Basal-HER2 Phenotype Shows Poorer Survival than BasalLike Phenotype in Hormone Receptor-Negative Invasive Breast Cancers," Human Pathology, Vol. 39, No. 2, 2008, pp. 167-174. doi:10.1016/j.humpath.2007.06.012

[16] B. Van Calster, I. VandenBempt, M. Drijkoningen, N. Pochet, J. Cheng, S. Van Huffel, W. Hendrickx, J. Decock, H. J. Huang, K. Leunen, F. Amant, P. Berteloot, R. Paridaens, H. Wildiers, E. Van Limbergen, C. Weltens, D. Timmerman, T. Van Gorp, A. Smeets, W. Van den Bogaert, I. Vergote, M. R. Christiaens and P. Neven, "Axillary Lymph Node Status of Operable Breast Cancers by Combined Steroid Receptor and HER-2 Status: Triple Positive Tumours Are More Likely Lymph Node Positive," Breast Cancer Research and Treatment, Vol. 113, No. 1, 2009, pp. 181-187. doi:10.1007/s10549-008-9914-7

[17] M. J. Kim, J. Y. Ro, S. H. Ahn, H. H. Kim, S. B. Kim and G. Gong, "Clinicopathologic Significance of the BasalLike Subtype of Breast Cancer: A Comparison with Hormone Receptor and Her2/Neu-Overexpressing Phenotypes," Human Pathology, Vol. 37, No. 9, 2006, pp. 12171226. doi:10.1016/j.humpath.2006.04.015

[18] P. L. Nguyen, A. G. Taghian, M. S. Katz, A. Niemierko, R. F. AbiRaad, W. L. Boon, J. R. Bellon, J. S. Wong, B. L. Smith and J. R. Harris, "Breast Cancer Subtype Approximated by Estrogen Receptor, Progesterone Receptor, and HER-2 Is Associated with Local and Distant Recurrence after Breast-Conserving Therapy," Journal of Clinical Oncology, Vol. 26, No. 14, 2008, pp. 2373-2378. doi:10.1200/JCO.2007.14.4287

[19] K. D. Voduc, M. C. Cheang, S. Tyldesley, K. Gelmon, T. O. Nielsen and H. Kennecke, "Breast Cancer Subtypes and the Risk of Local and Regional Relapse," Journal of Clinical Oncology, Vol. 28, No. 10, 2010, pp.1684-1691. doi:10.1200/JCO.2009.24.9284

[20] F. Reyal, R. Rouzier, B. Depont-Hazelzet, M. A. Bollet, J. Y. Pierga, S. Alran, R. J. Salmon, V. Fourchotte, A. Vincent-Salomon, X. Sastre-Garau, M. Antoine, S. Uzan, B. Sigal-Zafrani and Y. De Rycke, "The Molecular Subtype Classification Is a Determinant of Sentinel Node Positivity in Early Breast Carcinoma," PLoS One, Vol. 6, No. 5, 2011, Article ID: e20297. doi:10.1371/journal.pone.0020297

[21] S. Buglioni, F. Di Filippo, I. Terrenato, B. Casini, E. Gallo, F. Marandino, C. L. Maini, R. Pasqualoni, C. Botti, S. Di Filippo, E. Pescarmona and M. Mottolese, "Quantitative Molecular Analysis of Sentinel Lymph Node May Be Predictive of Axillary Node Status in Breast Cancer Classified by Molecular Subtypes," PLoS One, Vol. 8, No. 3, 2013, Article ID: e58823. doi:10.1371/journal.pone.0058823

[22] C. Mazouni, F. Rimareix, M. C. Mathieu, C. Uzan, C. Bourgier, F. André, S. Delaloge and J. R. Garbay, "Outcome in Breast Molecular Subtypes According to Nodalstatus and Surgical Procedures," American Journal of Surgery, Vol. 205, No. 6, 2013, pp. 662-667.

doi:10.1016/j.amjsurg.2012.06.006
[23] A. E. Giuliano, K. K. Hunt, K. V. Ballman, P. D. Beitsch, P. W. Whitworth, P. W. Blumencranz, A. M. Leitch, S. Saha, L. M. McCall and M. Morrow, "Axillary Dissection vs No Axillary Dissection in Women with Invasive Breast Cancer and Sentinel Node Metastasis: A Randomized Clinical Trial," JAMA, Vol. 305, No. 6, 2011, pp. 569-575. doi:10.1001/jama.2011.90

[24] V. Galimberti, B. F. Cole, S. Zurrida, G. Viale, A. Luini, P. Veronesi, P. Baratella, C. Chifu, M. Sargenti, M. Intra, O. Gentilini, M. G. Mastropasqua, G. Mazzarol, S. Massarut, J. R. Garbay, J. Zgajnar, H. Galatius, A. Recalcati, D. Littlejohn, M. Bamert, M. Colleoni, K. N. Price, M. M. Regan, A. Goldhirsch, A. S. Coates, R. D. Gelber and U. Veronesi, "International Breast Cancer Study Group Trial 23-01 Investigators, "Axillary Dissection versus No Axillary Dissection in Patients with Sentinel-Node Micrometastases (IBCSG 23-01): A Phase 3 Randomised Controlled Trial," Lancet Oncology, Vol. 14, No. 4, 2013, pp. 297-305. doi:10.1016/S1470-2045(13)70035-4

[25] O. Gentilini and U. Veronesi, "Abandoning Sentinel Lymph Node Biopsy in Early Breast Cancer? A New Trial in Progress at the European Institute of Oncology of Milan (SOUND: Sentinel Node vs Observation after Axillary UltraSouND)," Breast, Vol. 21, No. 5, 2012, pp. 678681. doi:10.1016/j.breast.2012.06.013

[26] B. Bonanni, M. Puntoni, M. Cazzaniga, G. Pruneri, D. Serrano, A. Guerrieri-Gonzaga, Gennari A, M. S. Trabacca, V. Galimberti, P. Veronesi, H. Johansson, V. Aristarco, F. Bassi, A. Luini, M. Lazzeroni, C. Varricchio, G. Viale, P. Bruzzi, and A. Decensi, "Dual Effect of Metformin on Breast Cancer Proliferation in a Randomized Presurgical Trial," Journal of Clinical Oncology, Vol. 30, No. 21, 2012, pp. 2593-2600. doi:10.1200/JCO.2011.39.3769

[27] R. Yerushalmi, R. Woods, P. M. Ravdin, M. M. Hayes and K. A. Gelmon, "Ki67 in Breast Cancer: Prognostic and Predictive Potential," Lancet Oncology, Vol. 11, No. 2, 2010, pp. 174-183. doi:10.1016/S1470-2045(09)70262-1

[28] C. Strand, M. Bak, S. Borgquist, G. Chebil, A. K. Falck, M. L. Fjällskog, D. Grabau, I. Hedenfalk, K. Jirström, M. Klintman, P. Malmström, H. Olsson, L. Rydén, O. Stål, P. O. Bendahl and M. Fernö, "The Combination of Ki67, Histological Grade and Estrogen Receptor Status Identifies a Low-Risk Group among 1854 Chemo-Naïve Women with N0/N1 Primary Breast Cancer," Springerplus, Vol. 2. No. 1, 2013, p. 111. doi:10.1186/2193-1801-2-111

[29] A. Goldhirsch, W. C. Wood, A. S. Coates, R. D. Gelber, B. Thürlimann and H. J. Senn and Panel Members, "Strategies for Subtypes - Dealing with the Diversity of Breast Cancer: Highlights of the St. Gallen International Expert Consensus on the Primary Therapy of Early Breast Cancer 2011," Annals of Oncology, Vol. 22, No. 8, 2011, pp. 1736-1747. doi:10.1093/annonc/mdr304

[30] R. L. Jones, J. Salter, R. A'Hern, A. Nerurkar, M. Parton, J. S. Reis-Filho, I. E. Smith and M. Dowsett, "Relationship between Oestrogen Receptor Status and Proliferation in Predicting Response and Long-Term Outcome to Neoadjuvant Chemotherapy for Breast Cancer," Breast Cancer Research and Treatment, Vol. 119, No. 2, 2010, pp. 315-323. doi:10.1007/s10549-009-0329-x

[31] G. Contesso, H. Mouriesse, S. Friedman, J. Genin, D. Sar- 
razin and J. Rouesse, "The Importance of Histologicgrade in Long-Term Prognosis of Breast Cancer: A Study of 1010 Patients, Uniformly Treated at the Institut Gustave-
Roussy," Journal of Clinical Oncology, Vol. 5, No. 9, 1987, pp. 1378-1386. 